This is an author generated postprint of the article: Chan, C.-H., et al. (2015). "A generalized energy-based kinetic model for microwave-assisted extraction of bioactive compounds from plants." Separation and Purification Technology 143(0): 152-160. Doi:10.1016/j.seppur.2015.01.041

\title{
A generalized energy-based kinetic model for microwave-assisted extraction of bioactive compounds from plants
}

\author{
Chung-Hung Chan ${ }^{\text {a, } *}$, Jian-Jiun Lim ${ }^{\text {a }}$, Rozita Yusoff ${ }^{\text {a }}$, Gek-Cheng Ngoh ${ }^{\text {a }}$ \\ ${ }^{a}$ University of Malaya, Department of Chemical Engineering, 50603 Kuala Lumpur, Malaysia.
}

\begin{abstract}
:
By considering the absorbed power and energy based on heating power profile during extraction, a generalized model with washing coefficient $(b)$, diffusion coefficient $(k)$ and predictive parameter namely absorbed power density (APD) was developed for microwaveassisted extraction (MAE) at any operational heating modes. To study the model, MAE of flavonoids from cocoa (Theobroma cacao L.) leaves was conducted using the heating modes (constant-power, two-steps-power, intermittent-power and constant-temperature) at various microwave power (100-300 W) and extraction temperature $\left(50{ }^{\circ} \mathrm{C}\right.$ and $\left.70{ }^{\circ} \mathrm{C}\right)$. The results shows that the model $\left(b=0.5595\right.$ and $\left.k^{\prime}=0.01279 \mathrm{ml} / \mathrm{J}\right)$ is able to predict the normalised extraction yields of MAE at any heating modes, heating power, microwave system, extraction scale and batch of plant sample with less than $4 \%$ discrepancy. The accuracy of the prediction relies on particle size of sample $(0.25-0.60 \mathrm{~mm})$, type of extraction $(85 \%$ ethanol) and solvent to feed ratio $(50 \mathrm{ml} / \mathrm{g})$.
\end{abstract}

Keywords: absorbed power density (APD), absorbed energy density (AED), generalized model, heating modes, normalized extraction yield

\footnotetext{
*Corresponding author. Tel: +6017 7680611; Fax: +603 79675319; Email address: ch_chan@um.edu.my
} 


\section{Introduction}

Microwave-assisted extraction (MAE) is an advanced extraction technique which employs microwave heating in an extraction system. MAE has been widely employed to extract valuable active compounds from plant materials [1,2] and plant-based waste residues [3, 4]. In general, the performance of MAE depends on its operational mode of heating [5], e.g. constant-power heating, intermittent-power heating and constant-temperature heating. Constant-power MAE delivers persistent heating at specific power to extraction system and it is a known as the standard practice to extract thermally-stable active compounds [6]; intermittent-power MAE provides pulsed microwave heating at certain power which is efficient in extracting thermallabile compounds [7] while constant temperature MAE controls extraction temperature which enables the extraction of highly degradable active compounds [8]. These heating modes are broadly adopted in MAE as far as plant extraction is concerned. Thus, their kinetic modeling would provide insightful information on the extraction behaviors to facilitate the optimization and scaling up operations.

Empirical model such as film theory, chemical kinetic equation and other two-parametric models has been conventionally used to model assisted extraction techniques including MAE [9]. These models can only indicate the extraction kinetics at different operating conditions and extraction techniques as their extraction constants are obtained by curve-fitting through experimental data. Empirical models developed based on response surface methodology (RSM) and artificial neural network (ANN) had been applied to simulate and optimize the operating parameters of MAE [10, 11]. These models require lesser experimental data for the simulation as compared to conventional empirical MAE model. However, screening of suitable range of operating parameters is essential to achieve reliable optimization results. Modeling of MAE had been attempted using transport equations such as Maxwell's, energy and species 
balance equations via COMSOL Multiphysics ${ }^{\mathrm{TM}}$ software [12]. Both the distribution of electromagnetic wave and temperature profile for constant-power and intermittent-power MAE can be simulated theoretically based on the model, whereas their extraction profiles can only be modeled based on experimentally-fitted empirical parameters [12]. All the models mentioned employ empirical approach to model the mass transport phenomenon of MAE process. They are applicable only at specific operating condition, heating mode and microwave system. To broaden the predictive capability of MAE model, two energy-related parameters namely absorbed power density (APD) and absorbed energy density (AED) had been introduced and were incorporated into conventional empirical model as parameters to predict the extraction profile of MAE at various microwave powers and extraction scales [13]. These energy-related parameters, i.e. APD and AED are indicators for heating performance of MAE and the progress of the extraction to reach equilibrium state, respectively. Beside the involvement in modeling study, APD and AED can also be adopted in the optimization of MAE at various extraction scale [14]. This validated APD-AED predictive model is applicable only for constant-power MAE and its predictive capabilities in various heating modes and extraction system have yet to be confirmed.

In this study, the absorbed power and energy of a MAE system at each heating steps based on its heating-power profile was taken into account in the development of the generalized predictive model to study the MAE of flavonoids from cocoa (Theobroma cacao L.) leaves at constant power, two steps power, intermittent power and constant temperature heating. The capabilities of the model to predict the extraction profile of MAE were evaluated at various conditions such as at different heating power, heating modes and microwave system. This work also analyzes the intrinsic effects exerted by the APD and AED parameters on the extraction mechanism of MAE. 


\section{Materials and Methods}

\subsection{Materials and reagents}

Denatured alcohol was obtained from LGC Scientific co. (Malaysia) as extraction solvent. Standard of flavonoid compounds such as isoquercitrin, (-)-epicatechin and rutin were purchased from Sigma-Aldrich co. (USA). Acetonitrile and ethanol are purchased from Merck co. (Germany) as mobile phase for chromatography analysis.

\subsection{Sample preparation}

Fresh cocoa leaves collected from local cocoa plantation were dried using conventional airdrying oven at $40{ }^{\circ} \mathrm{C}$ for a day. The dried leaves (5-6\% moisture content) were then cut and powdered to $0.25-0.60 \mathrm{~mm}$ particle size and stored at $4{ }^{\circ} \mathrm{C}$ in a container.

\subsection{Microwave-assisted extraction at various heating modes}

Two (2) g of cocoa leaves sample was mixed with $100 \mathrm{ml}$ of $85 \%$ (v/v) aqueous ethanol (optimum solvent) in a $500 \mathrm{ml}$ closed Duran bottle. The mixture was put inside a microwave system and heated up using predetermined operating conditions based on certain heating-power profile as shown in Fig. 1. In this study, domestic microwave oven (Samsung MW718) was employed to perform constant-power, two-steps-power and intermittent-power MAE at various microwave power ranging from 100-300 W. In constant-power MAE, the extraction mixture was heated up using fixed power without stirring; two-steps power MAE involved sequential heating using two power levels and the intermittent-power MAE provided pulsed heating at fixed power. The latter heating mode was adjusted by turning on and off the microwave system based on intermittency ratio, $\alpha=\tau_{\text {on }} /\left(\tau_{\text {on }}+\tau_{\text {on }}\right)$ [7], where $\tau_{\text {on }}$ and $\tau_{\text {off }}$ are the respective on and off periods (min) of each cycle (one on plus one off periods). On the other hand, temperature- 
controlled microwave system (Milestone RotoSYNTH) was used to carry out constanttemperature MAE at $50{ }^{\circ} \mathrm{C}$ and $70{ }^{\circ} \mathrm{C}$. In this MAE, microwave power of $500 \mathrm{~W}$ was applied to ramp up the extraction temperature to the desired set point. After the desired temperature was reached, the extraction temperature was maintained by regulating the nominal microwave power. Upon subjected to certain mode of heating, the extraction mixture was cooled down to room temperature using a water bath. The extract was filtered using fine cloth followed by 0.2 $\mu \mathrm{m}$ regenerated cellulose filter prior to HPLC analysis. To construct an extraction profile of MAE, extractions at predetermined operating conditions were conducted at varying extraction times using fresh samples.

(a)

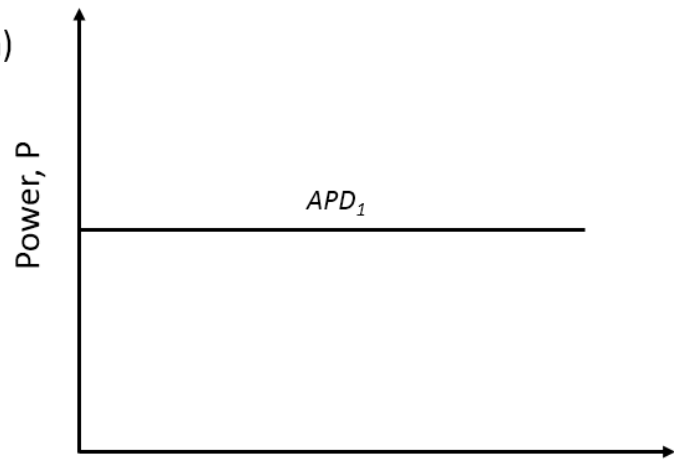

Extraction time, $\mathrm{t}$

(c)

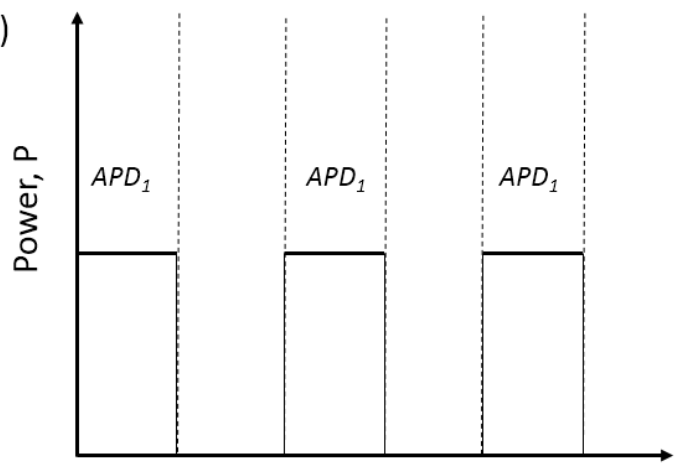

Extraction time, $\mathrm{t}$ (b)

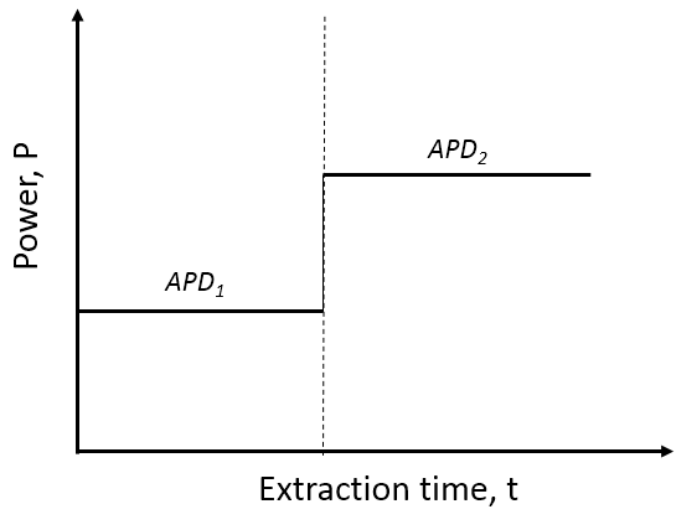

(d)

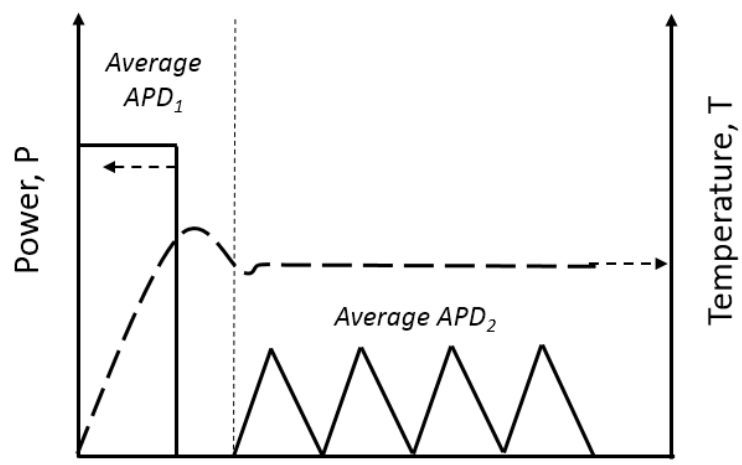

Extraction time, $\mathrm{t}$

Fig. 1: Heating-power profiles of various operational modes of MAE: (a) constant power heating; (b) two-steps power heating; (c) intermittent power heating; (d) constant temperature heating. 


\subsection{Quantification of flavonoids in cocoa leaves extract}

High performance liquid chromatography (HPLC) was performed to quantify three flavonoid compounds from cocoa leaves extract. Agilent 1200 Series HPLC device with Agilent ZORBAX Eclipse Plus C18 column, $5 \mu \mathrm{m}(4.6 \mathrm{~mm} \times 150 \mathrm{~mm})$ configured with Bonaccorsi $e t$ al. method [15] was employed in this analysis. The flavonoids was analysed at $350 \mathrm{~nm}$ for isoquercitrin and rutin compounds and $280 \mathrm{~nm}$ for (-)-epicatechin compound using UV-DAD detector. Mobile phase used in this analysis consists of linear gradient of acetonitrile in water: 5-20\% (0-15 min), 20-30\% (15-20 min), 30-50\% (20-30 min), 50-100\% (30-35 min), 100\% (35-40 $\mathrm{min})$, and $100-5 \%(40-50 \mathrm{~min})$ at flow rate of $1.0 \mathrm{ml} / \mathrm{min}$. The extraction yield is expressed as the mass of extracted active compounds (mg) per mass of sample used ( $\mathrm{g}$ ). The total extraction yields of isoquercitrin, (-)-epicatechin and rutin were the response of the modeling study.

\subsection{Determination of energy-related parameters}

The proposed model relies on values of absorbed power density (APD) and absorbed energy density (AED) of the MAE system at various heating powers. APD and AED represent the absorbed microwave power $(\mathrm{W} / \mathrm{ml})$ and absorbed microwave energy $(\mathrm{J} / \mathrm{ml})$ per unit solvent volume, respectively. The detail procedure for the determination of APD and AED was reported in the previous work [13]. APD can be determined experimentally by measuring the absorbed power of a blank extraction solvent heated using a specific nominal microwave power based on Eq. (1).

$$
A P D=\frac{Q}{V \cdot t_{H}}
$$

where $Q$ is the total energy absorbed by solvent during heating $(\mathrm{J}), V$ is the solvent volume $(\mathrm{ml})$ and $t_{H}$ is the heating time (min). The total heat absorbed, $Q$ can be calculated from the evolved temperature profile based on heat capacity of the solvent. In this study, a representative value 
of APD of blank extraction solvent under various nominal microwave power were determined by averaging the APD values calculated for each conditions at different heating time $\left(t_{H}\right)$. Due to fluctuation in microwave irradiation power during constant-temperature MAE, the APD values were determined based on two average microwave powers, i.e. the power to ramp the extraction temperature to desired set point and the power to maintain the desired temperature across the time as indicated in Fig. 1. The calculated average APD values of MAE systems are tabulated in Table 1. The energy-related parameter, AED is related to APD and the extraction time via Eq. (2).

$A E D_{t}=A P D \times t$

where $A E D_{t}$ is the total microwave energy absorbed per solvent volume during the extraction $(\mathrm{J} / \mathrm{ml})$ and $t$ is the extraction time (min).

Table 1: APD values of MAE systems

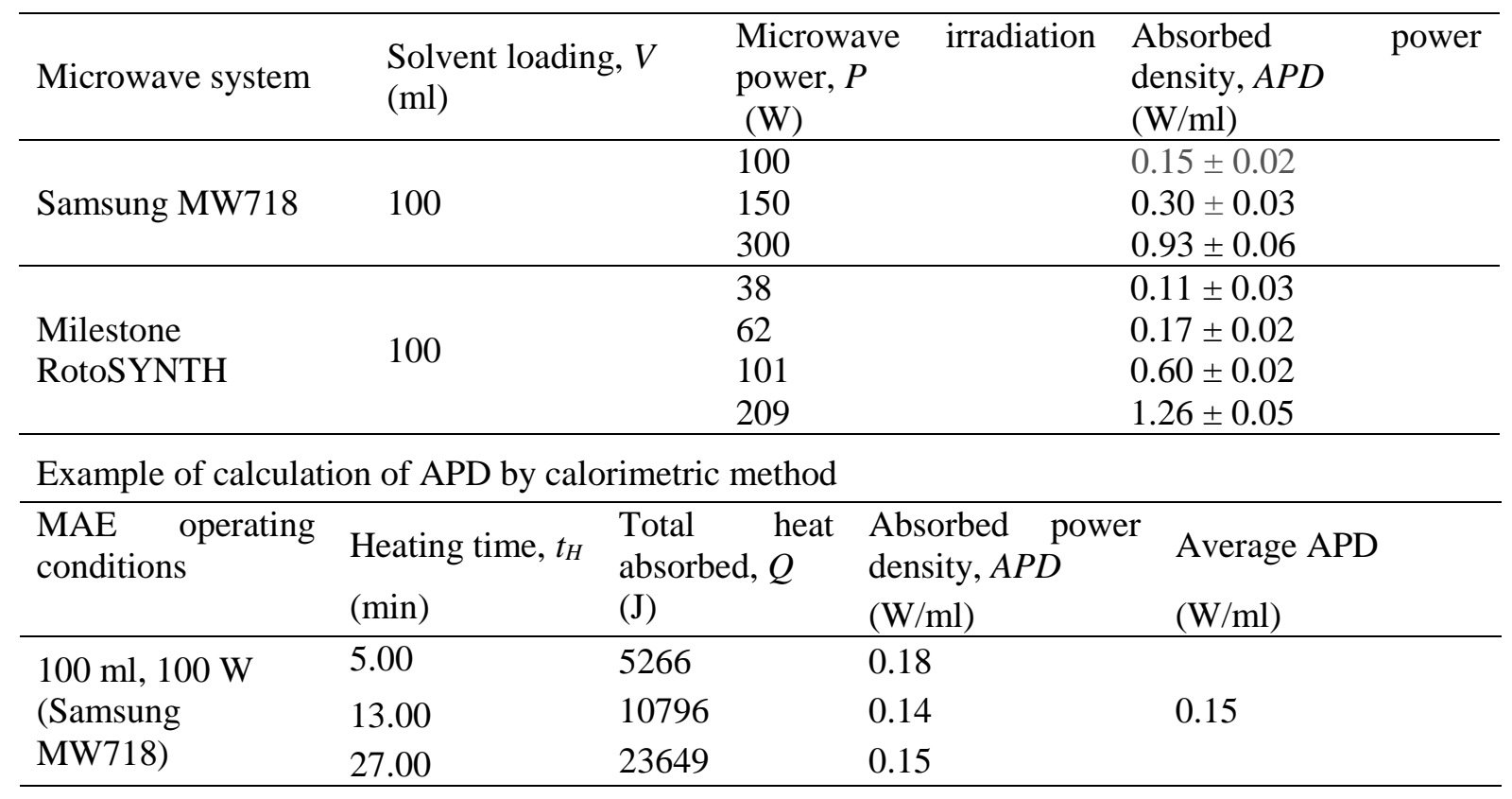




\subsection{Generalized energy-based MAE model}

The typical extraction profile, i.e. yield vs. time of MAE consists of two stages. The first stage involves the washing of active compounds from the broken plant cells by the bulk solvent in a fast rate due to sample preparation e.g. grinding and in the second stage, the diffusion of active compounds from the microwave-ruptured cells into the bulk solvent. This study focuses only on the diffusion stage as this stage is strongly influenced by the operating conditions of MAE. Film theory model [16] as expressed in Eq. (3) is suitable to model the normalized extraction yield of the diffusion stage.

\section{Film theory model}

$$
Y=\frac{y}{y_{s}}=1-(1-b) \exp (-k \cdot t)
$$

where $Y$ is the normalized extraction yield, $y$ is the extraction yield $(\mathrm{mg} / \mathrm{g}), y_{s}$ is the equilibrium extraction yield (mg/g), $b$ and $k$ indicate the extraction kinetics for the washing (1) and diffusion $\left(\mathrm{min}^{-1}\right)$ stages, respectively. By adapting Eq. (3) with AED as a basis to replace the extraction time $t$, a simple energy-based model can be developed to simulate the progress of a MAE to reach equilibrium extraction stage based on the amount of microwave energy absorbed in the system as follows:

\section{$\underline{\text { AED-film theory model }}$}

$$
Y=\frac{y}{y_{s}}=1-(1-b) \exp \left(-k^{\prime} \cdot A E D_{t}\right)
$$

where $k$ is the kinetic constants for the diffusion stage in energy basis $(\mathrm{ml} / \mathrm{J})$. The simulated energy-based extraction profile, i.e. normalized yield vs. AED is generally applicable over constant-power MAE operated at any heating conditions [13]. This model can be rewritten in Eq. (5) to predict the normalized extraction profile in time basis based on the actual heating power of the MAE system (APD value). 


\section{Predictive AED-film theory model}

$Y=\frac{y}{y_{s}}=1-(1-b) \exp \left(-k^{\prime} \cdot A P D \cdot t\right)$

To extend the applicability of this model to two-steps-power, intermittent-power and constanttemperature MAE, the APD values of each heating steps involved in the MAE were incorporated into the model as illustrated in Fig. 2. As a result, a generalized energy-based MAE model was proposed to describe the normalized extraction yield of MAE at $i$ th heating step, $Y_{i}$ as shown in Eq. (6)

Generalized predictive AED-film theory model

$$
Y_{i}(t)=\frac{y}{y_{s}}=1-\left(1-b_{i}\right) \exp \left[-k_{i} \cdot\left(t-\sum_{j=0}^{i-1} \tau_{j}\right)\right]
$$

where $\tau$ is the total time period in a heating step, $b_{i}$ and $k_{i}$ are the washing and diffusion coefficient at $i$ th heating step, respectively. The individual washing and diffusion coefficients involved in each heating steps can respectively be calculated using Eq. (7) and Eq. (8):

$b_{i}=Y_{i-1}\left(\tau_{i-1}\right)=1-\left(1-b_{i-1}\right) \exp \left(-k^{\prime} \cdot A P D_{i-1} \cdot \tau_{i-1}\right)$, where $b_{1}=b$

$k_{i}=k^{\prime} \times A P D_{i}$

The coefficient $b_{i}$ indicates the final extraction yield obtained at previous $i$ - $l$ th heating step whereas the coefficient $k_{i}$ is calculated based on the APD value at the $i$ th heating step. 


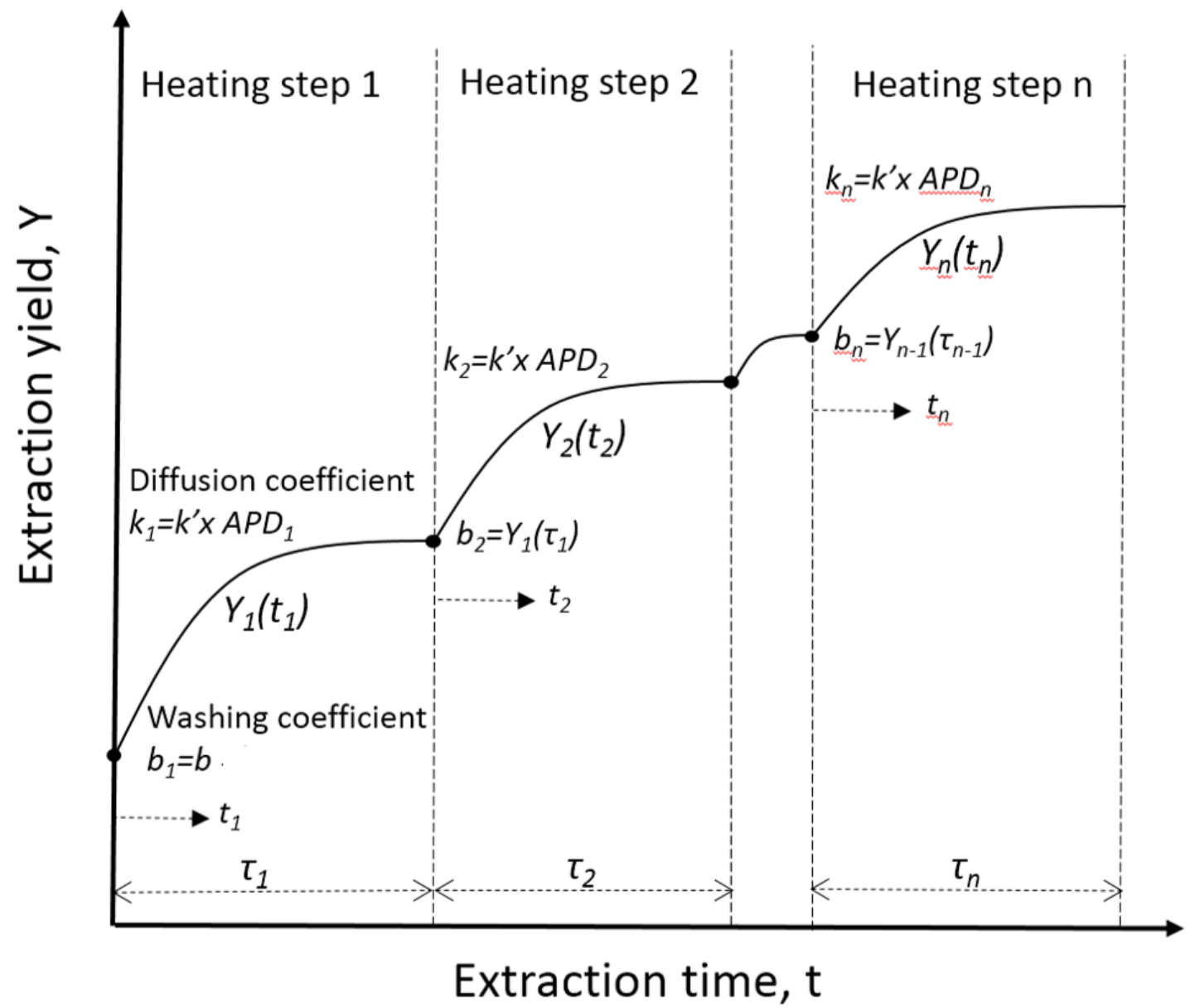

Fig. 2: Schematic diagram of the development of generalized predictive film theory-APD model.

\subsection{Evaluation of the applicability of the model}

The extraction profile of constant-power MAE in Table 2 (No. 1) was used to calibrate the model's coefficients, i.e. the initial washing coefficient, $b$ and the energy-based diffusion coefficient, $k$ '. The coefficients were determined by curve-fitting Eq. (4) with the experimental data using Matlab curve fitting toolbox (version 2.1). The coefficients were then substituted into Eq. (6-8) to predict the extraction curves of two-steps-power, intermittent-power and constant-temperature MAE as tabulated in Table 2 (No. 2-7) based on their APD values involved in the extraction. The goodness of fit for the predictions were evaluated based on the average relative error $(\%)$ by comparing with the experimental data. 
Table 2: Experimental design for extraction curves of MAE

\begin{tabular}{|c|c|c|c|c|c|c|}
\hline \multirow{2}{*}{ No. } & \multirow{2}{*}{$\begin{array}{l}\text { Heating } \\
\text { modes }\end{array}$} & \multirow{2}{*}{ Heating conditions } & \multicolumn{3}{|c|}{ Equilibrium extraction yields (mg/g) } & \multirow{2}{*}{$\begin{array}{l}\text { Total } \\
\text { equilibrium } \\
\text { extraction } \\
\text { yield }(\mathrm{mg} / \mathrm{g})\end{array}$} \\
\hline & & & IQ & $\mathrm{EC}$ & RT & \\
\hline 1 & $\begin{array}{l}\text { Constant } \\
\text { power }\end{array}$ & Samsung MW718; $150 \mathrm{~W}, 20 \mathrm{~min}$ & $2.35 \pm 0.02$ & $2.59 \pm 0.03$ & $4.89 \pm 0.06$ & $9.82 \pm 0.07$ \\
\hline 2 & & $\begin{array}{l}\text { Samsung MW718; step 1: } 100 \mathrm{~W} \text {, } \\
13.46 \mathrm{~min} \text {; step 2: } 300 \mathrm{~W}, 4.14 \mathrm{~min}\end{array}$ & $2.55 \pm 0.01$ & $2.80 \pm 0.01$ & $5.15 \pm 0.05$ & $10.50 \pm 0.05$ \\
\hline 3 & power & $\begin{array}{l}\text { Samsung MW718; step 1: } 300 \mathrm{~W} \text {, } \\
3.20 \mathrm{~min} \text {; step 2: } 100 \mathrm{~W}, 6.40 \mathrm{~min}\end{array}$ & $2.62 \pm 0.02$ & $2.76 \pm 0.07$ & $5.27 \pm 0.03$ & $10.65 \pm 0.12$ \\
\hline 4 & Intermittent & $\begin{array}{l}\text { Samsung MW718; } 150 \mathrm{~W}, \alpha=0.50 \\
\text { (on: } 4 \mathrm{~min} \text {, off: } 4 \mathrm{~min} \text { ) for } 32 \mathrm{~min}\end{array}$ & $2.31 \pm 0.09$ & $2.49 \pm 0.01$ & $5.08 \pm 0.02$ & $9.89 \pm 0.11$ \\
\hline 5 & power & $\begin{array}{l}\text { Samsung MW718; } 300 \mathrm{~W}, \alpha=0.25 \\
\text { (on: } 1 \mathrm{~min} \text {, off: } 3 \mathrm{~min} \text { ) for } 16 \mathrm{~min}\end{array}$ & $2.38 \pm 0.01$ & $2.52 \pm 0.03$ & $5.02 \pm 0.05$ & $9.93 \pm 0.10$ \\
\hline 6 & & $\begin{array}{l}\text { Milestone RotoSYNTH; } 500 \mathrm{~W} \\
\text { (ramping for } 25 \mathrm{sec} \text { ), } 50^{\circ} \mathrm{C}, 30 \mathrm{~min}\end{array}$ & $2.04 \pm 0.09$ & $2.66 \pm 0.07$ & $5.10 \pm 0.02$ & $9.79 \pm 0.06$ \\
\hline 7 & temperature & $\begin{array}{l}\text { Milestone RotoSYNTH; } 500 \mathrm{~W} \\
\text { (ramping for } 40 \mathrm{sec} \text { ), } 70^{\circ} \mathrm{C}, 15 \mathrm{~min}\end{array}$ & $2.20 \pm 0.04$ & $2.67 \pm 0.11$ & $5.13 \pm 0.06$ & $10.00 \pm 0.18$ \\
\hline
\end{tabular}

\section{Results and Discussion}

\subsection{Calibration of model parameters}

The initial washing coefficient $b$ and the energy-based diffusion coefficient $k$ ' in Eq. (4) were calibrated based on constant-power MAE at $150 \mathrm{~W}$ as shown in Fig. 3. Approximately 56\% out of total yield was obtained at the beginning of the extraction before heating. The coefficient $k^{\prime}(0.01279 \mathrm{ml} / \mathrm{J})$ obtained at $150 \mathrm{~W}$ in this study is close to that reported at $100 \mathrm{~W}$ in the previous work $(0.01452 \mathrm{ml} / \mathrm{J})[13]$. This suggests that the initial washing coefficient $b$ and the energy-based diffusion coefficient $k^{\prime}$ are constant regardless of the heating power. Theoretically, they are affected only by the operating parameters such as extraction solvent, solvent to feed ratio and particle size of sample that have no direct effect on the microwave 
heating. This is because extraction solvent that affects the microwave absorption capability also at the same time, affects the solubility of the active compounds whereas solvent to feed ratio controls the accessibility of solvent to dissolve the compounds and sample particle size has an effect on the diffusion of the active compounds from the plant matrices. After calibration, the model coefficients obtained at $b=0.5595$ and $k^{\prime}=0.01279 \mathrm{ml} / \mathrm{J}$ were substituted in Eq. (6-8) to predict the extraction profile of MAE conducted using various heating modes, heating powers and microwave systems.

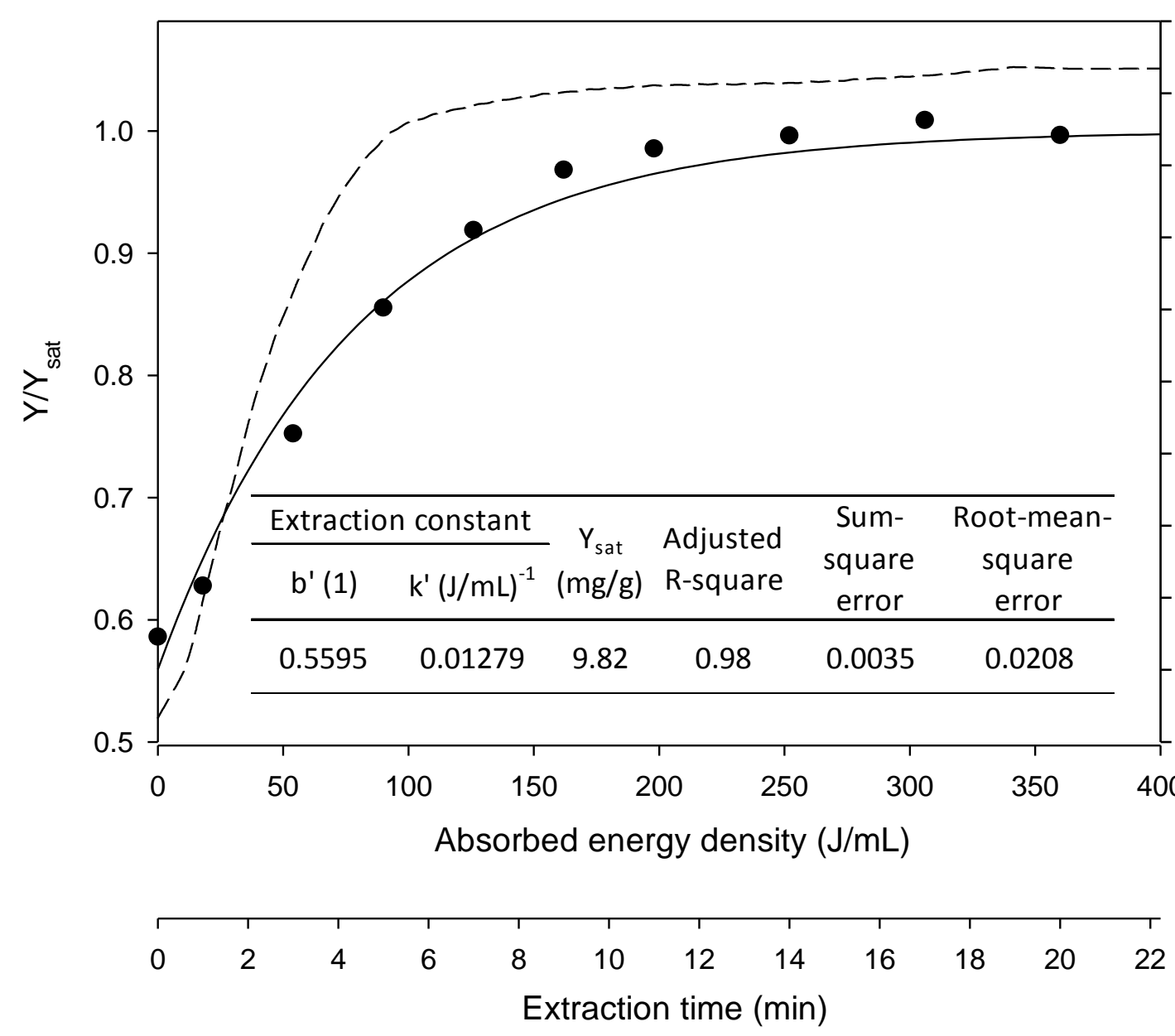

Fig. 3: Determination of the coefficients of film theory-AED model based on curve fitting; MAE conditions: constant power heating of $150 \mathrm{~W}$ and APD of $0.3 \mathrm{~W} / \mathrm{mL}$; • experimental extraction yield; - fitted extraction curve; - - solvent temperature. 


\subsection{Predictive capability of the generalized model}

Based on constructed model Eq. (8-10), the individual washing and diffusion coefficients of MAE at two steps power, intermittent power and constant temperature heating were calculated and tabulated in Table 3. All the predicted extraction profiles are able to capture the trends of the experimental extraction profiles as the average relative error in most cases was less than 4\%. This indicates that the generalized model is feasible in predicting the MAE kinetics by adapting suitable diffusion coefficient according to the heating power involved in the extraction. As observed in Table 3, the diffusion coefficient $k$ is strongly influenced by the heating power employed or the APD parameter. The performance of the generalized model, related extraction mechanism and the intrinsic effects of APD and AED parameters on each operational heating modes are elaborated accordingly.

\subsubsection{Two-steps-power MAE}

The extraction profiles of two-steps-power MAE at power configuration of 100-300 W and 300-100 W were predicted by the generalized model as depicted in Fig. 4. The extraction profiles exhibit similar trend with respective to their temperature profiles consisting of two distinct regions with different growth rates. Both the temperature and extraction profiles are dependent on the heating power of MAE as higher APD conditions for faster heating and extraction rate. An interesting findings on MAE using two steps power is that it gives the highest equilibrium extraction yields among operational heating modes as shown in Table 2. At least 5\% additional extraction yields can be achieved using this heating mode regardless of the order of the power configuration at low-high or high-low power level. This implicated that MAE conducted using two steps power heating is more effective than continuous heating at fixed power to heat up the dielectric content and disrupt the plant cells. The effectiveness of two-steps-power MAE resulted in evaporation of more than $30 \%$ (vol.) of extraction solvent 
as the extraction temperature was constantly at the boiling point of the solvent (about $70{ }^{\circ} \mathrm{C}$ ) due to rapid heating.

Table 3: Predictive capability of generalized predictive AED-film theory model in MAE

\begin{tabular}{|c|c|c|c|c|}
\hline \multirow{2}{*}{$\begin{array}{l}\text { Operational } \\
\text { heating mode }\end{array}$} & \multirow{2}{*}{ Heating steps } & \multicolumn{2}{|c|}{ Predicted extraction constant } & \multirow{2}{*}{$\begin{array}{l}\text { Average } \\
\text { relative } \\
\text { error }(\%)\end{array}$} \\
\hline & & $\mathrm{b}(1)$ & $\mathrm{k}(\min )^{-1}$ & \\
\hline \multirow{2}{*}{$\begin{array}{l}\text { Two-steps } \\
\text { power } \\
\text { heating }\end{array}$} & $\begin{array}{l}\text { (1) } 100 \mathrm{~W}(0.15 \mathrm{~W} / \mathrm{ml}), 13.46 \mathrm{~min} \\
\text { (2) } 300 \mathrm{~W}(0.93 \mathrm{~W} / \mathrm{ml}), 4.14 \mathrm{~min}\end{array}$ & $\begin{array}{l}\mathrm{b}_{1}=0.5595 \\
\mathrm{~b}_{2}=0.9064\end{array}$ & $\begin{array}{l}\mathrm{k}_{1}=0.1151 \\
\mathrm{k}_{2}=0.7137\end{array}$ & 3.18 \\
\hline & $\begin{array}{l}\text { (1) } 300 \mathrm{~W}(0.93 \mathrm{~W} / \mathrm{ml}), 3.20 \mathrm{~min} \\
\text { (2) } 100 \mathrm{~W}(0.15 \mathrm{~W} / \mathrm{ml}), 16.40 \mathrm{~min}\end{array}$ & $\begin{array}{l}\mathrm{b}_{1}=0.5595 \\
\mathrm{~b}_{2}=0.9551\end{array}$ & $\begin{array}{l}\mathrm{k}_{1}=0.7137 \\
\mathrm{k}_{2}=0.1151\end{array}$ & 2.93 \\
\hline \multirow{2}{*}{$\begin{array}{l}\text { Intermittent } \\
\text { power } \\
\text { heating }\end{array}$} & $\begin{array}{l}\text { (1) } 150 \mathrm{~W}(0.30 \mathrm{~W} / \mathrm{ml}), 4 \mathrm{~min} \\
\text { (2) } 0 \mathrm{~W}, 4 \mathrm{~min} \\
\text { (3) } 150 \mathrm{~W}(0.30 \mathrm{~W} / \mathrm{ml}), 4 \mathrm{~min} \\
\text { (4) } 0 \mathrm{~W}, 4 \mathrm{~min} \\
\text { (5) } 150 \mathrm{~W}(0.30 \mathrm{~W} / \mathrm{ml}), 4 \mathrm{~min} \\
\text { (6) } 0 \mathrm{~W}, 4 \mathrm{~min} \\
\text { (7) } 150 \mathrm{~W}(0.30 \mathrm{~W} / \mathrm{ml}), 4 \mathrm{~min} \\
\text { (8) } 0 \mathrm{~W}, 4 \mathrm{~min}\end{array}$ & $\begin{array}{l}\mathrm{b}_{1}=0.5595 \\
\mathrm{~b}_{2}=0.8246 \\
\mathrm{~b}_{3}=0.8246 \\
\mathrm{~b}_{4}=0.9302 \\
\mathrm{~b}_{5}=0.9302 \\
\mathrm{~b}_{6}=0.9722 \\
\mathrm{~b}_{7}=0.9722 \\
\mathrm{~b}_{8}=0.9889\end{array}$ & $\begin{array}{l}\mathrm{k}_{1}=0.2302 \\
\mathrm{k}_{2}=0 \\
\mathrm{k}_{3}=0.2302 \\
\mathrm{k}_{4}=0 \\
\mathrm{k}_{5}=0.2302 \\
\mathrm{k}_{6}=0 \\
\mathrm{k}_{7}=0.2302 \\
\mathrm{k}_{8}=0\end{array}$ & 2.52 \\
\hline & $\begin{array}{l}\text { (1) } 300 \mathrm{~W}(0.93 \mathrm{~W} / \mathrm{ml}), 1 \mathrm{~min} \\
\text { (2) } 0 \mathrm{~W}, 3 \mathrm{~min} \\
\text { (3) } 300 \mathrm{~W}(0.93 \mathrm{~W} / \mathrm{ml}), 1 \mathrm{~min} \\
\text { (4) } 0 \mathrm{~W}, 3 \mathrm{~min} \\
\text { (5) } 300 \mathrm{~W}(0.93 \mathrm{~W} / \mathrm{ml}), 1 \mathrm{~min} \\
\text { (6) } 0 \mathrm{~W}, 3 \mathrm{~min} \\
\text { (7) } 300 \mathrm{~W}(0.93 \mathrm{~W} / \mathrm{ml}), 1 \mathrm{~min} \\
\text { (8) } 0 \mathrm{~W}, 3 \mathrm{~min}\end{array}$ & $\begin{array}{l}\mathrm{b}_{1}=0.5595 \\
\mathrm{~b}_{2}=0.7842 \\
\mathrm{~b}_{3}=0.7842 \\
\mathrm{~b}_{4}=0.8943 \\
\mathrm{~b}_{5}=0.8943 \\
\mathrm{~b}_{6}=0.9482 \\
\mathrm{~b}_{7}=0.9482 \\
\mathrm{~b}_{8}=0.9746\end{array}$ & $\begin{array}{l}\mathrm{k}_{1}=0.7137 \\
\mathrm{k}_{2}=0 \\
\mathrm{k}_{3}=0.7137 \\
\mathrm{k}_{4}=0 \\
\mathrm{k}_{5}=0.7137 \\
\mathrm{k}_{6}=0 \\
\mathrm{k}_{7}=0.7137 \\
\mathrm{k}_{8}=0\end{array}$ & 2.10 \\
\hline \multirow{2}{*}{$\begin{array}{l}\text { Constant } \\
\text { temperature } \\
\text { heating }\end{array}$} & $\begin{array}{l}\text { Extraction temperature of } 50^{\circ} \mathrm{C} \\
\text { (1) Average } 101 \mathrm{~W}(0.60 \mathrm{~W} / \mathrm{ml}), 2 \mathrm{~min} \\
\text { (2) Average } 38 \mathrm{~W}(0.08 \mathrm{~W} / \mathrm{ml}), 28 \mathrm{~min}\end{array}$ & $\begin{array}{l}\mathrm{b}_{1}=0.5595 \\
\mathrm{~b}_{2}=0.8246\end{array}$ & $\begin{array}{l}\mathrm{k}_{1}=0.4604 \\
\mathrm{k}_{2}=0.0844\end{array}$ & 4.09 \\
\hline & $\begin{array}{l}\text { Extraction temperature of } 70{ }^{\circ} \mathrm{C} \\
\text { (1) Average } 209 \mathrm{~W}(1.26 \mathrm{~W} / \mathrm{ml}), 2 \mathrm{~min} \\
\text { (2) Average } 71 \mathrm{~W}(0.20 \mathrm{~W} / \mathrm{ml}), 13 \mathrm{~min}\end{array}$ & $\begin{array}{l}b_{1}=0.5595 \\
b_{2}=0.9363\end{array}$ & $\begin{array}{l}\mathrm{k}_{1}=0.9669 \\
\mathrm{k}_{2}=0.1305\end{array}$ & 3.35 \\
\hline
\end{tabular}


(a)

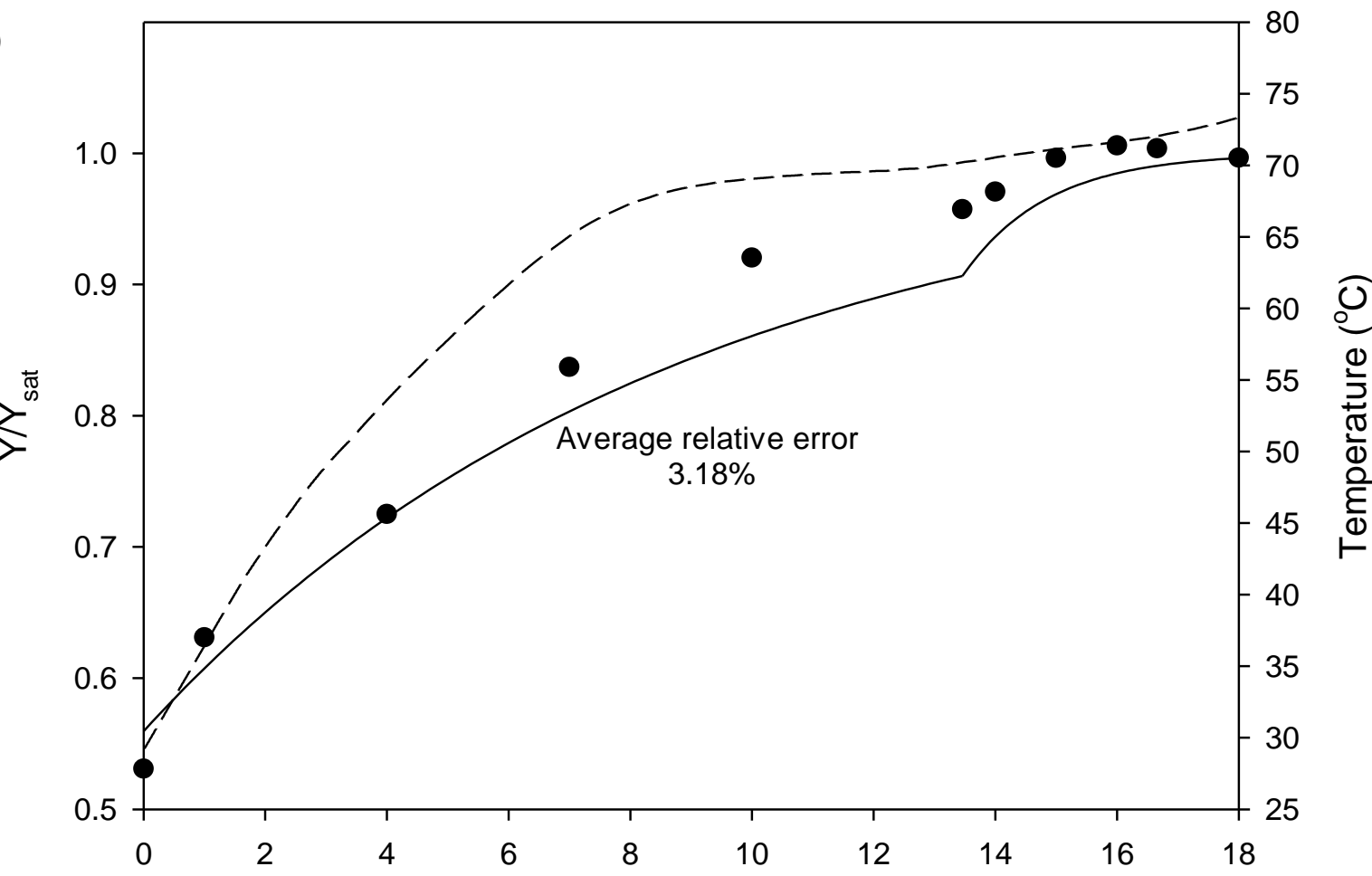

(b)

Extraction time ( $\mathrm{min})$

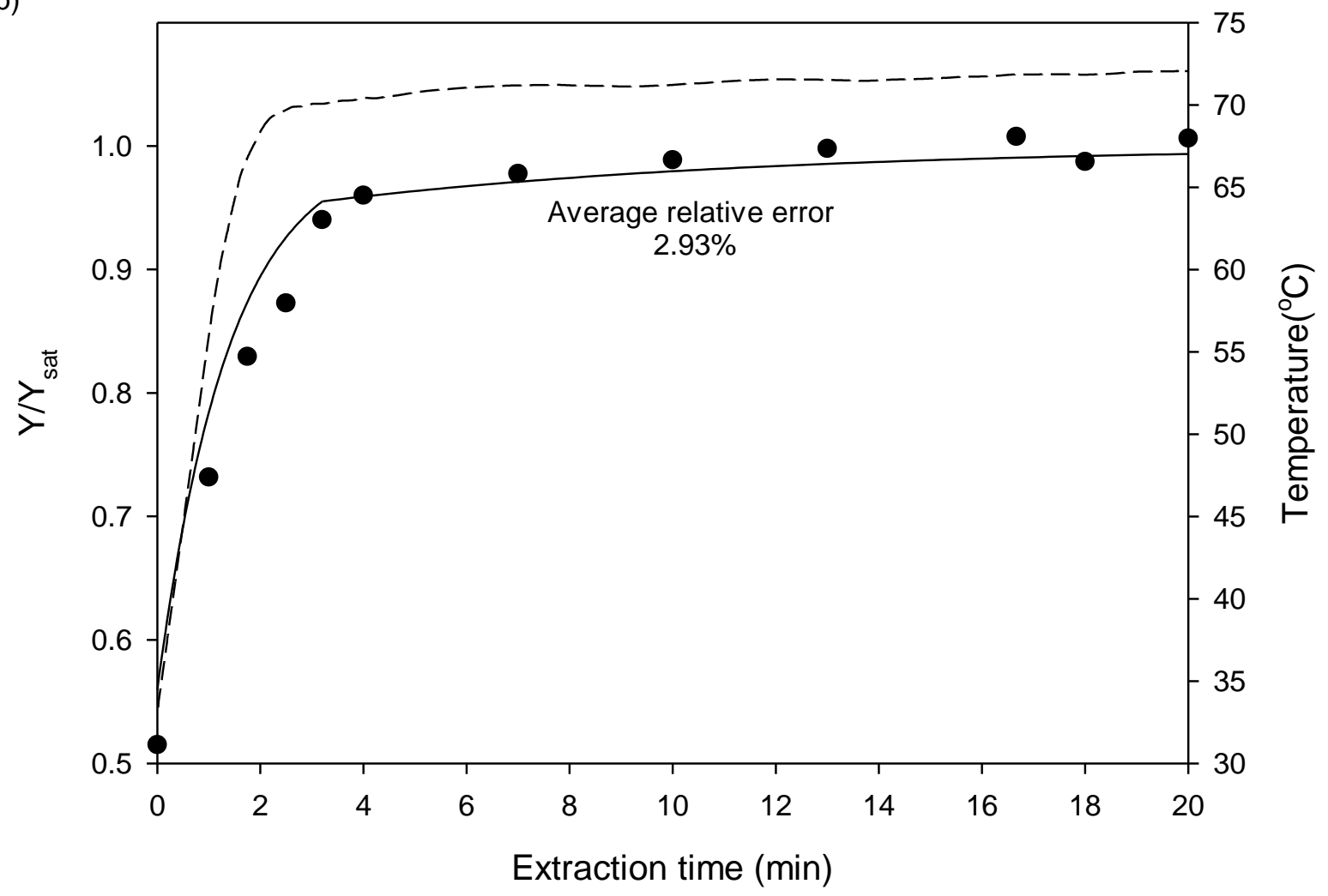

Fig. 4: Prediction of extraction curve of MAE at two steps power heating: (a) $100 \mathrm{~W}$ for 13.46 min followed by $300 \mathrm{~W}$ for $4.14 \mathrm{~min}$; (b) $300 \mathrm{~W}$ for $3.20 \mathrm{~min}$ followed by $100 \mathrm{~W}$ for 16.40 min; • experimental extraction yield; - predicted extraction curve; - - solvent temperature. 


\subsubsection{Intermittent-power MAE}

The MAE was also conducted in intermittent power heating mode at $150 \mathrm{~W}$ and $300 \mathrm{~W}$ to evaluate the predictive ability of the proposed model. Intermittent-power MAE gave similar extraction yield as the constant-power MAE (refer to Table 2) but at lower extraction temperature and lesser solvent evaporation (less than 10\% vol.). Fig. 5 shows that the predicted extraction curves were close to the experimental data, in which the trend increased during microwave heating and stabilized across the off heating period. Their respective temperature profiles also follow similar stepwise increment trend. This implies that extraction occurs in MAE during the presence of microwave heating disregards of its extraction temperature. Microwave heating is associated to the mechanism of disrupting plant cells [17], whereas extraction temperature affects both the thermal stability of active compounds [18] and also the rate of diffusion due to concentration gradient effect as described in Fick's law of diffusion [19], As the mechanism of rupturing plant cells is relatively more significant than the concentration-gradient diffusion mechanism in MAE process, it is justified to emphasize only on the cell rupture mechanism for future theoretical modeling. 
(a)

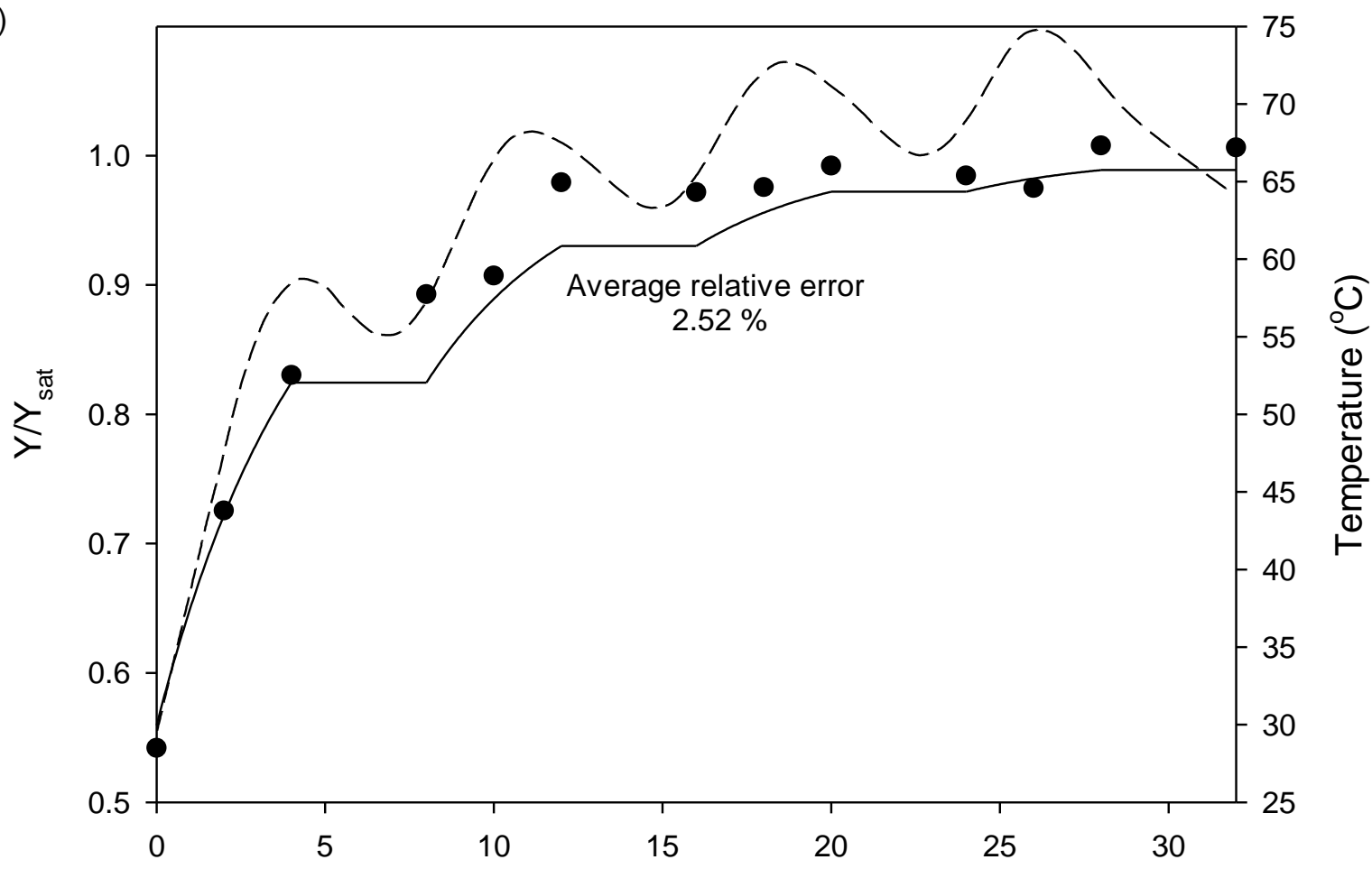

(b)

Extraction time (min)

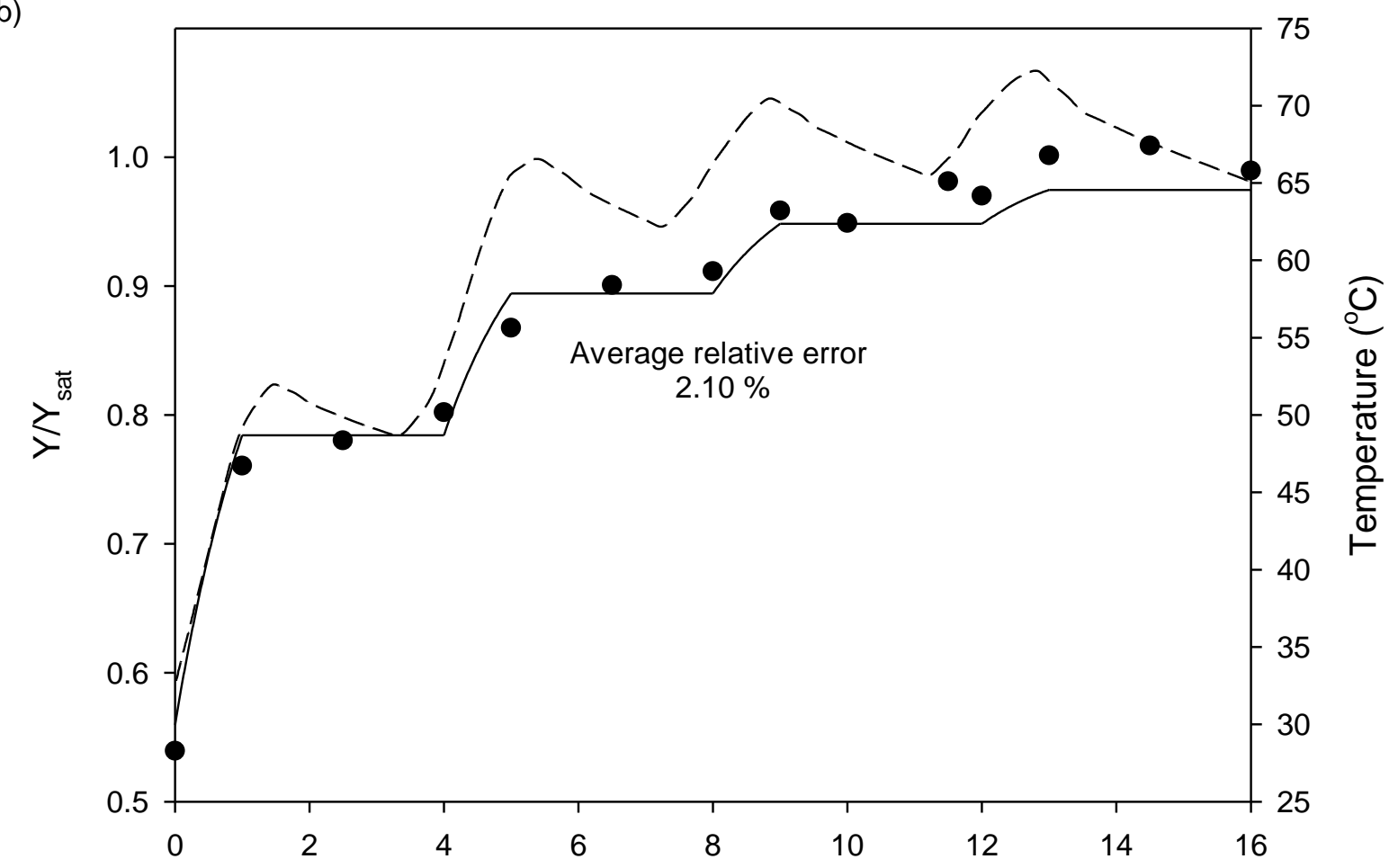

Extraction time (min)

Fig. 5: Prediction of extraction curve of MAE at intermittent power heating: (a) $150 \mathrm{~W}, \alpha=$ 0.50 (on: $4 \mathrm{~min}$, off: $4 \mathrm{~min}$ ) for $32 \mathrm{~min}$; (b) $300 \mathrm{~W}, \alpha=0.25$ (on: $1 \mathrm{~min}$, off: $3 \mathrm{~min}$ ) for $16 \mathrm{~min}$; - experimental extraction yield; - predicted extraction curve; - - solvent temperature. 


\subsubsection{Constant-temperature MAE}

The constant-temperature MAE at $50{ }^{\circ} \mathrm{C}$ and 70 were conducted to evaluate the performance of the proposed model. Based on their irradiation power and temperature profiles in Fig. 6, the average microwave power to ramp the extraction temperature up to $50{ }^{\circ} \mathrm{C}$ and $70{ }^{\circ} \mathrm{C}$ were 101 $\mathrm{W}$ for $209 \mathrm{~W}$ respectively. Meanwhile, the respective average powers to maintain the desired temperatures were $38 \mathrm{~W}$ and $62 \mathrm{~W}$. By using APD values computed based on these average powers, the proposed model is able to predict the extraction profiles of constant-temperature MAE conducted using a different microwave system with great accuracy as illustrated in Fig. 6. This signifies that the proposed model is applicable to any microwave system attributing to the intrinsic property of APD parameter [14]. The extraction trend observed in Fig.6 are not different from the previous two-steps-power MAE, whereby two distinct growth rates were observed. Considering the performance of constant-temperature MAE, there is no significant advantage in terms of the equilibrium extraction yield, extraction time and solvent evaporation as compared to that of the intermittent-power MAE. It should be noted that this MAE requires shorter extraction time at higher temperature operation, which is due to higher average power involved in the system and not because of temperature effects as explained in the case of intermittent-power MAE previously. 
(a)

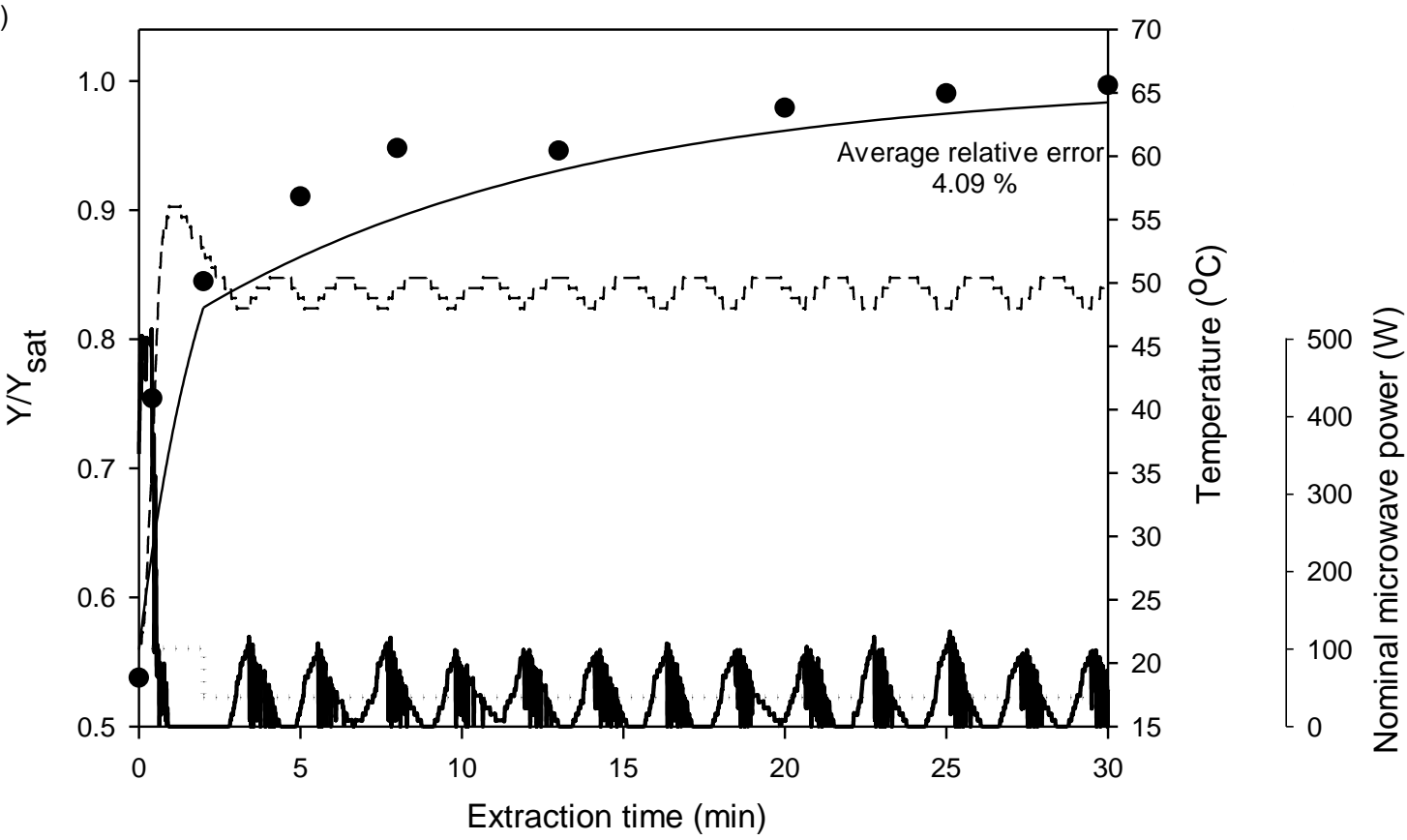

(b)

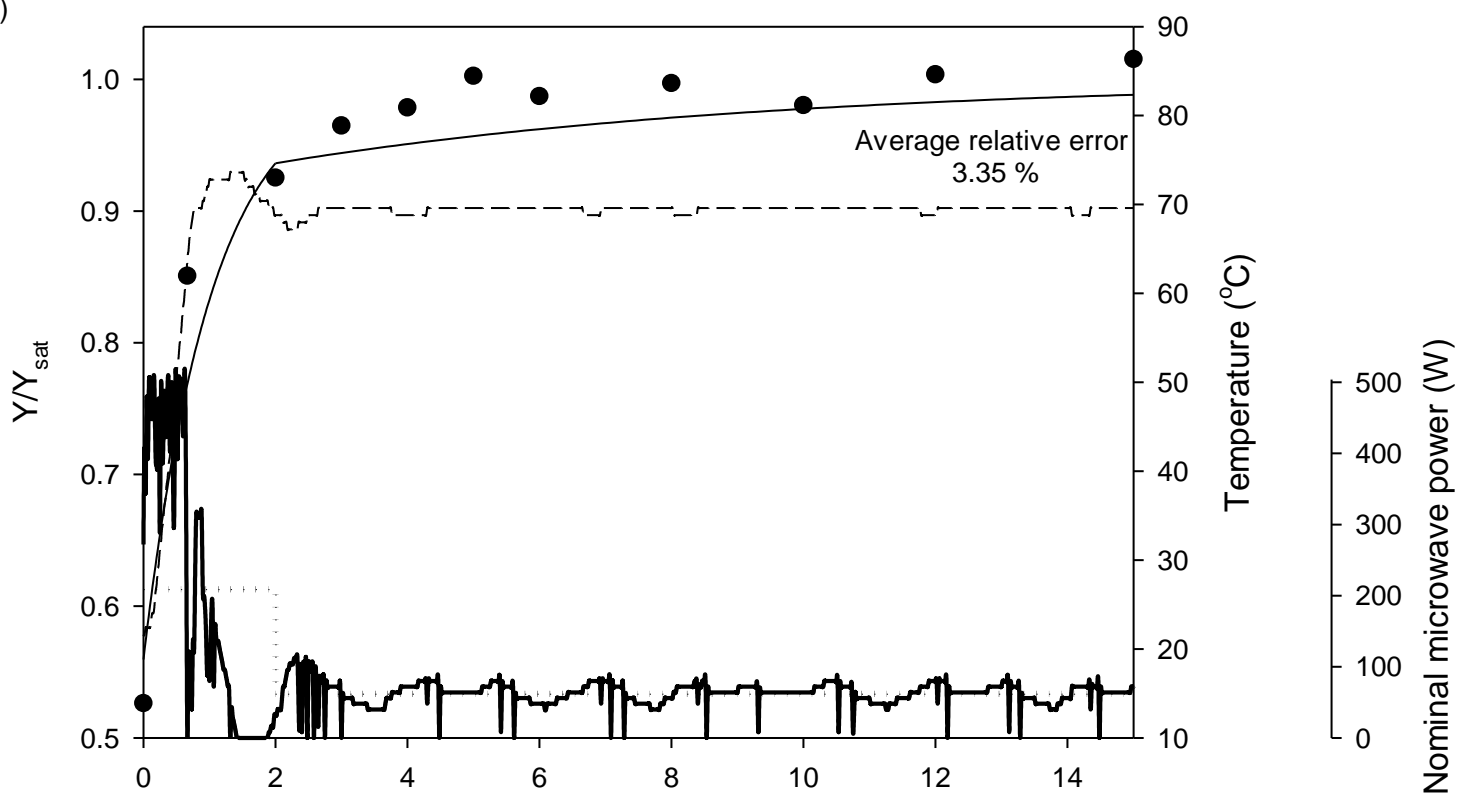

Extraction time (min)

Fig. 6: Prediction of extraction curve of MAE at constant temperature heating: (a) $500 \mathrm{~W}$ (ramping for $25 \mathrm{sec}$ ), $50{ }^{\circ} \mathrm{C}, 30 \mathrm{~min}$; (b) $500 \mathrm{~W}$ (ramping for $40 \mathrm{sec}$ ), $70{ }^{\circ} \mathrm{C}, 15 \mathrm{~min}$; experimental extraction yield; - predicted extraction curve; - - solvent temperature; nominal power; $\bullet \bullet$ average nominal power. 


\subsection{Energy-performance curve of MAE}

The selection of operational heating mode of MAE is crucial as it affects the performance of MAE. Both constant-power and two-steps power MAE are suitable for extracting thermallystable active compounds. However, two-steps power mode gives slightly higher equilibrium extraction yields due to rapid heating. On the other hand, intermittent-power and constanttemperature MAE can be applied to the extraction involving thermal-sensitive compounds and low boiling point solvent such as methanol as they can operate at milder temperature condition. The performance of a MAE at any operational modes and heating conditions can be determined based on the energy-performance curve obtained for the specific plant-based extraction. The curve is plotted corresponded to the normalized extraction yield and AED of the extraction system. Normalized yield indicates the degree of completion of an extraction whereas AED indicates the amount of input microwave energy required for the MAE system to achieve specific extraction performance. To further elaborate, AED used in this context refers to the energy required to heat up an extraction solvent to facilitate the cell rupture mechanism.

In this study, the energy-performance curve of MAE for the extraction of flavonoids from cocoa leaves is shown in Fig. 7. The plot shows that the normalized extraction yield of the MAEs conducted at various heating modes, heating powers and microwave setups are aligned with their respective AED values. Similar to the previous study [13], whereby three performance regions under the effect of AED are identified as steady diffusion (AED $<100$ $\mathrm{J} / \mathrm{ml}$ ), equilibrium region (100 J/ml $<$ AED $<300 \mathrm{~J} / \mathrm{ml}$ ) and overheating (AED>300 J/ml). This signifies that AED affects the MAE intrinsically and its effect is consistent regardless of the heating mode employed. The energy performance curve in Fig. 7 can be used to predict the optimum extraction time of MAE conducted at any heating mode, heating power, extraction scale and microwave system based on the amount of energy absorbed in the solvent. However, 
the prediction cannot be applied to MAE with different particle size of sample, extraction solvent and solvent to feed ratio as the effects of the mentioned variables are not addressed by AED and APD. This further implicated that reproducibility of the extraction results of MAE can be ensured by providing the details of APD, AED, size of plant sample used, type of extraction solvent and solvent to feed ratio when reporting the experiment in the literature. In brief, the AED-kinetic model $\left(b=0.5595\right.$ and $\left.k^{\prime}=0.01279 \mathrm{ml} / \mathrm{J}\right)$ presented in Fig. 7 is specifically for MAE of flavonoids from $0.25-0.60 \mathrm{~mm}$ cocoa leaves sample using $85 \%(\mathrm{v} / \mathrm{v})$ aqueous ethanol at ratio of $50 \mathrm{ml} / \mathrm{g}$.

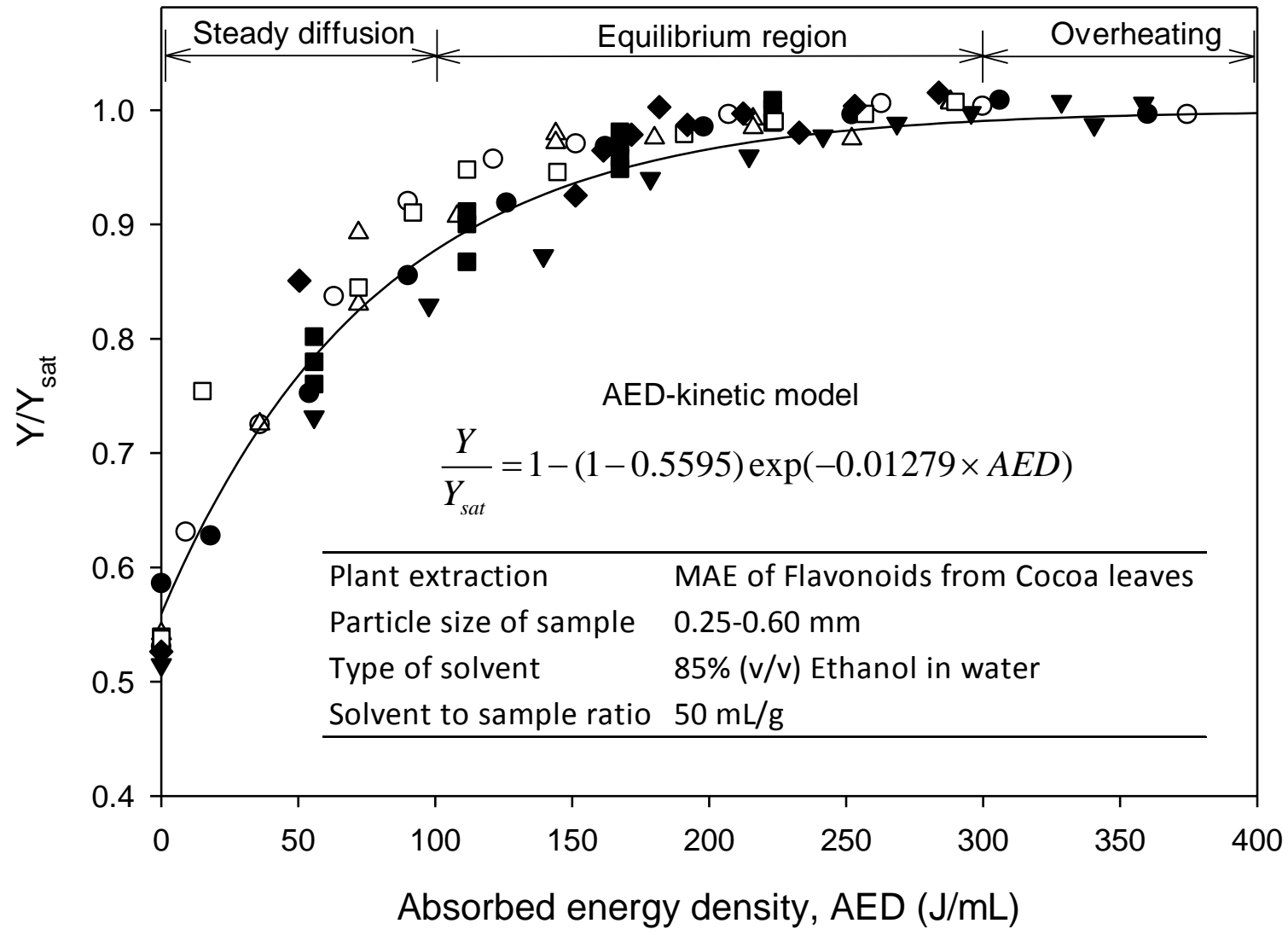

Fig. 7: Energy-performance curve of MAE of flavonoids compounds from cocoa leaves; constant power heating at $150 \mathrm{~W}(20 \mathrm{~min})$; o two-steps power heating at $100 \mathrm{~W}(13.46 \mathrm{~min})$ followed by $300 \mathrm{~W}(4.14 \mathrm{~min})$; $\boldsymbol{\nabla}$ two-steps power heating at $300 \mathrm{~W}(3.20 \mathrm{~min})$ followed by $100 \mathrm{~W}(6.40 \mathrm{~min}) ; \Delta$ intermittent power heating at $150 \mathrm{~W}, \alpha=0.50(32 \mathrm{~min})$; intermittent power heating at $300 \mathrm{~W}, \alpha=0.25(16 \mathrm{~min})$; $\square$ constant temperature heating at $50{ }^{\circ} \mathrm{C}(30 \mathrm{~min})$;

$\checkmark$ constant temperature heating at $70{ }^{\circ} \mathrm{C}(15 \mathrm{~min})$. 


\section{Conclusion}

A generalized energy-based kinetic model was developed for the MAE of bioactive compounds from plants. This model can be used to predict the extraction profiles of MAE at various heating modes based on the absorbed power density (APD) involved in the extraction. The model prediction is applicable to any extraction scale, heating power and microwave system of MAE thus is useful for optimization and scaling up. From the energy-performance curve, i.e. normalized yield vs absorbed energy density (AED) obtained from this model, the reproducibility of MAE at any operational mode for a specific plant extraction is guaranteed based on five operating parameters: APD, AED, size of plant sample used, type of extraction solvent and solvent to feed ratio.

\section{Acknowledgements}

This work was performed under the Centre for Separation Science and Technology (CSST), University of Malaya and financially supported through University of Malaya Research Grant (UMRG:RP002A-13AET).

\section{References}

[1] D.-T. Xie, Y.-Q. Wang, Y. Kang, Q.-F. Hu, N.-Y. Su, J.-M. Huang, C.-T. Che, J.-X. Guo, Microwave-assisted extraction of bioactive alkaloids from Stephania sinica, Sep. Purif. Technol. 130 (2014) 173-181.

[2] R. Upadhyay, K. Ramalakshmi, L. Jagan Mohan Rao, Microwave-assisted extraction of chlorogenic acids from green coffee beans, Food Chem. 130 (2012) 184-188.

[3] A.A. Casazza, B. Aliakbarian, S. Mantegna, G. Cravotto, P. Perego, Extraction of phenolics from Vitis vinifera wastes using non-conventional techniques, J. Food Eng. 100 (2010) 50-55. 
[4] A. Baiano, L. Bevilacqua, C. Terracone, F. Contò, M.A. Del Nobile, Single and interactive effects of process variables on microwave-assisted and conventional extractions of antioxidants from vegetable solid wastes, J. Food Eng. 120 (2014) 135-145.

[5] C.-H. Chan, R. Yusoff, G.-C. Ngoh, F.W.-L. Kung, Microwave-assisted extractions of active ingredients from plants, J. Chromatogr. A 1218 (2011) 6213-6225.

[6] B.G. Terigar, S. Balasubramanian, D. Boldor, Z. Xu, M. Lima, C.M. Sabliov, Continuous microwave-assisted isoflavone extraction system: Design and performance evaluation, Bioresour. Technol. 101 (2010) 2466-2471.

[7] B. Hiranvarachat, S. Devahastin, Enhancement of microwave-assisted extraction via intermittent radiation: Extraction of carotenoids from carrot peels, J. Food Eng. 126 (2014) 1726.

[8] A. Tsukui, H.M. Santos Júnior, S.S. Oigman, R.O.M.A. de Souza, H.R. Bizzo, C.M. Rezende, Microwave-assisted extraction of green coffee oil and quantification of diterpenes by HPLC, Food Chem. 164 (2014) 266-271.

[9] C.-H. Chan, R. Yusoff, G.-C. Ngoh, Modeling and kinetics study of conventional and assisted batch solvent extraction, Chem. Eng. Res. Des. 92 (2014) 1169-1186.

[10] K. Sinha, S. Chowdhury, P.D. Saha, S. Datta, Modeling of microwave-assisted extraction of natural dye from seeds of Bixa orellana (Annatto) using response surface methodology (RSM) and artificial neural network (ANN), Ind. Crop. Prod. 41 (2013) 165-171.

[11] K. Sinha, P.D. Saha, S. Datta, Response surface optimization and artificial neural network modeling of microwave assisted natural dye extraction from pomegranate rind, Ind. Crop. Prod. 37 (2012) 408-414.

[12] N. Chumnanpaisont, C. Niamnuy, S. Devahastin, Mathematical model for continuous and intermittent microwave-assisted extraction of bioactive compound from plant material: Extraction of $\beta$-carotene from carrot peels, Chem. Eng. Sci. 116 (2014) 442-451. 
[13] C.-H. Chan, R. Yusoff, G.-C. Ngoh, Modeling and prediction of extraction profile for microwave-assisted extraction based on absorbed microwave energy, Food Chem. 140 (2013) 147-153.

[14] C.-H. Chan, R. Yusoff, G.-C. Ngoh, Optimization of microwave-assisted extraction based on absorbed microwave power and energy, Chem. Eng. Sci. 111 (2014) 41-47.

[15] P. Bonaccorsi, C. Caristi, C. Gargiulli, U. Leuzzi, Flavonol glucosides in Allium species: A comparative study by means of HPLC-DAD-ESI-MS-MS, Food Chem. 107 (2008) 16681673.

[16] I.T. Stanisavljević, M.L. Lazić, V.B. Veljković, Ultrasonic extraction of oil from tobacco (Nicotiana tabacum L.) seeds, Ultrason. Sonochem. 14 (2007) 646-652.

[17] Y. Kong, Y.-G. Zu, Y.-J. Fu, W. Liu, F.-R. Chang, J. Li, Y.-H. Chen, S. Zhang, C.-B. Gu, Optimization of microwave-assisted extraction of cajaninstilbene acid and pinostrobin from pigeonpea leaves followed by RP-HPLC-DAD determination, J. Food Compos. Anal. 23 (2010) 382-388.

[18] M. Biesaga, Influence of extraction methods on stability of flavonoids, J. Chromatogr. A 1218 (2011) 2505-2512.

[19] R.B. Bird, W.E. Stewart, E.N. Lightfoot, Transport phenomena, John Wiley and Sons, Inc., New York, 1960. 